\title{
IMPACTOS DA APLICAÇÃO DE BIOSSÓLIDOS NA MICROBIOTA DE SOLOS TROPICAIS ${ }^{(1)}$
}

\author{
Marcio Rodrigues Lambais ${ }^{(2)} \&$ Janaina Braga do Carmo ${ }^{(3)}$
}

\begin{abstract}
RESUMO
A aplicação de biossólidos de Estações de Tratamento de Esgotos (ETEs) em solos agrícolas e florestais tem sido uma das práticas alternativas preconizadas para a reciclagem desses resíduos orgânicos. No entanto, alguns biossólidos de ETEs podem conter metais e, ou, xenobiontes que poderiam afetar a microbiota. Neste trabalho, os impactos da aplicação de biossólidos das ETEs de Barueri e Franca (SP), com alta e baixa concentração de metais, respectivamente, na microbiota de um solo argiloso (Nitossolo Vermelho eutroférrico típico) e um arenoso (Neossolo Quartzarênico órtico típico) foram determinados em condições de microcosmos. Imediatamente após a adição de diferentes doses de biossólidos ao solo, e depois de 4, 8, 16, 32 e 64 dias de incubação, a respiração basal (RB), C na biomassa microbiana (CB), quociente metabólico $\left(q \mathrm{CO}_{2}\right)$ e relação $\mathrm{CB} / \mathrm{C}$-orgânico do solo (CB/Corg) foram avaliados. No geral, a RB foi maior nos solos com maiores quantidades de biossólidos, sendo os maiores acréscimos verificados logo após a aplicação dos biossólidos. No solo arenoso, decréscimos significativos do CB foram observados nos tratamentos com as doses mais elevadas de biossólidos. $\mathrm{O} q \mathrm{CO}_{2}$ foi maior nos solos com doses mais elevadas de biossólidos, mas diminuiu com o aumento do período de incubação. Independentemente do tipo de solo, $\mathrm{CB} / \mathrm{C}_{\text {org }}$ foi maior nos solos que não receberam biossólidos, em relação aos solos que receberam biossólidos ricos em metais. A relação $\mathrm{CB} / \mathrm{C}_{\text {org }}$ nos solos tratados com biossólidos ricos em metais diminuiu significativamente entre 4 e 16 dias de incubação, não sofrendo alterações posteriormente. Esses dados indicam que a aplicação de biossólidos nos solos analisados, independentemente do teor de metais, pode causar um estresse transiente na comunidade microbiana, dependendo da dose aplicada, e que alterações na estrutura das comunidades microbianas podem estar ocorrendo.
\end{abstract}

Termos para indexação: biossólidos, biomassa microbiana, metal pesado, atividade microbiana, carbono orgânico.

(1) Parte da dissertação de mestrado da segunda autora, apresentada ao Programa de Pós-Graduação em Solos e Nutrição de Plantas, Escola Superior de Agricultura "Luiz de Queiroz" - ESALQ. Recebido para publicação em abril de 2007 e aprovado em março de 2008 .

(2) Professor Associado do Departamento de Ciência do Solo, Caixa Postal 09, Av. Pádua Dias 11, CEP 13418-900 Piracicaba (SP). Email: mlambais@esalq.usp.br

${ }^{(3)}$ Professor Adjunto da Universidade de São Carlos - UFSCar. Campus Sorocaba, Rodovia João Leme dos Santos SP 264, Km 110, Bairro Itinga, CEP 18052-780 Sorocaba (SP). Email: jbcarmo@ufscar.br 


\title{
SUMMARY: IMPACTS OF BIOSOLIDS AMENDMENTS ONTHE MICROBIOTA OF TROPICAL SOILS
}

\begin{abstract}
The amendment of agricultural and forest soils with biosolids from sewage treatment plants $\left(S T P_{S}\right)$ is an alternative to recycle these organic residues. However, biosolids from STPS may contain metals and/or xenobiotics that can affect soil microorganisms. In this study, the impacts of biosolids from the STPs of Barueri and Franca (São Paulo, Brazil), containing high and low metal concentration, respectively, on the microbiota of a Nitisol (clayey) and a Dystric Arenosol (sandy) were determined in microcosm. Immediately after biosolids application and 4, 8, 16, 32 and 64 days after incubation, the basal respiration (BR), $C$ in microbial biomass $(C B)$, metabolic quotient $\left(\mathrm{q} C \mathrm{O}_{2}\right.$ ), and $\mathrm{CB} /$ soil organic $C$ ratio $\left(C B / C_{\text {org }}\right)$ were evaluated. In general, $R B$ was higher in soils amended with the highest amounts of biosolids, and the greatest increments were observed immediately after biosolids application. In the sandy soil, statistically significant decreases in $C B$ were observed in the treatments with the highest amounts of biosolids. The $\mathrm{qCO}_{2}$ was higher in soils with the highest amounts of biosolids, but decreased during incubation. Regardless of the soil type, $\mathrm{CB} / \mathrm{C}_{\text {org }}$ was higher in soils without biosolids when compared to soils with metal-rich biosolids. The $C B / C_{\text {org }}$ ratio in soils amended with metal-rich biosolids decreased significantly between 4 and 16 days after incubation, and leveled off thereafter. These data indicate that the amendment of the tested soils with biosolids, independently of the metal content, may cause a transient stress in the microbial community, depending on the applied dose, and that changes in the structure of the microbial communities may have occurred.
\end{abstract}

Index terms: biosolids, microbial biomass, heavy metal, microbial activity, organic carbon.

\section{INTRODUÇÃO}

Os biossólidos são resíduos orgânicos gerados durante o processo de tratamento biológico de águas residuárias, compostos basicamente de biomassa microbiana sedimentável. Apesar de sua composição química variável, os biossólidos são ricos em matéria orgânica e nutrientes essenciais para as plantas e microrganismos. Dependendo da origem das águas residuárias, os biossólidos podem conter quantidades elevadas de metais, como $\mathrm{Zn}, \mathrm{Cu}$ e $\mathrm{Cd}$, e, ou, xenobiontes, além de microrganismos patogênicos a animais e humanos.

No Brasil, a possibilidade de geração de grandes quantidades de biossólidos provenientes de estações de tratamento de esgoto (ETEs) nos próximos anos tem causado preocupação, e soluções alternativas para sua reciclagem têm sido avaliadas. Dentre essas soluções, sua aplicação em solos agrícolas e florestais é a forma de reciclagem mais promissora.

A aplicação de biossólidos nos solos pode contribuir para o aumento da concentração de nutrientes essenciais, como $\mathrm{N}$ e $\mathrm{P}$, e para o melhoramento dos atributos físicos de solos altamente intemperizados. No entanto, dependendo da origem do biossólido, o aumento da concentração de metais pesados como e, ou, xenobiontes pode contribuir para a contaminação do solo e acarretar possível efeito deletério em plantas e microrganismos (Fliebbach et al., 1994; Leita et al., 1995; Vig et al., 2003).
Vários atributos microbiológicos têm sido utilizados para avaliar impactos de potenciais poluentes sobre a microbiota dos solos. Dentre esses atributos, a quantidade de $\mathrm{C}$ na biomassa microbiana (CB), a atividade respiratória basal da microbiota (RB), o quociente metabólico $\left(q \mathrm{CO}_{2}\right)$ e a relação entre o $\mathrm{CB}$ e o C orgânico do solo ( $\mathrm{CB} / \mathrm{C}_{\text {org }}$ ) são os mais comuns (Brookes, 1995; Leita et al., 1995; Lambais et al., 2005). No geral, a aplicação de biossólidos de ETEs com baixa concentração de metais pesados ao solo tem efeitos positivos sobre a biomassa e atividade da microbiota, enquanto biossólidos com altas concentrações de metais pesados podem provocar reduções na biomassa e em sua atividade (McGrath et al., 1985; Fliebbach et al., 1994; Kandeler et al., 1996; Sastre et al., 1996; Banerjee et al., 1997; Knight et al., 1997).

A contaminação do solo com metais pesados pode também resultar em diminuição da diversidade genética e alteração da estrutura das comunidades microbianas (Frostegård et al., 1993; Torsvik et al., 1998; Sandaa et al., 1999; Gans et al., 2005). Em solos contaminados com As e $\mathrm{Cd}$, alterações na estrutura da comunidade de bactérias, avaliadas por meio da separação de fragmentos do gene rRNA 16S por eletroforese em gel com gradiente desnaturante (DGGE), e inibição de atividades de fosfatase alcalina, arilsulfatase, protease e urease, em relação ao controle não contaminado, foram observadas (Lorenz et al., 2006). A diminuição dessas atividades enzimáticas nos solos tratados com metais pode ser atribuída à redução 
da eficiência do metabolismo microbiano em condições de estresse (Renella et al., 2005b).

Muito embora os biossólidos de ETEs sejam amplamente utilizados na agricultura, principalmente nos EUA e Europa, seus efeitos sobre a microbiota dos solos são variáveis e devem ser avaliados em diferentes condições edáficas. Os microrganismos do solo têm papel essencial na ciclagem de nutrientes, formação do húmus, degradação de xenobiontes, formação e manutenção da estabilidade de agregados e fluxo de gases, dentre outras funções (Lambais et al., 2005; Carmo et al., 2005). Assim, processos que interfiram na diversidade genética e, ou, funcional da microbiota dos solos podem contribuir para a alteração de sua qualidade (Lambais et al., 2005).

O objetivo deste trabalho foi determinar os impactos da aplicação de biossólidos de ETEs com baixa e alta concentração de metais pesados sobre a microbiota de um solo arenoso e outro argiloso.

\section{MATERIAL E MÉTODOS}

\section{Solos}

Nos ensaios, foram utilizados um solo de textura arenosa (Neossolo Quartzarênico órtico típico) e outro de textura argilosa (Nitossolo Vermelho eutroférrico típico) da região de Piracicaba (SP). As amostras de solo foram retiradas da camada de $0-20 \mathrm{~cm}$ de profundidade e homogeneizadas antes dos ensaios. Os atributos químicos e físicos dos solos utilizados são apresentados no quadro 1.

Quadro 1. Atributos químicos e físicos dos solos utilizados nos experimentos

\begin{tabular}{|c|c|c|}
\hline \multirow{2}{*}{ Atributo } & \multicolumn{2}{|c|}{ Solo } \\
\hline & Arenoso & Argiloso \\
\hline $\mathrm{pH}\left(\mathrm{CaCl}_{2}\right)$ & 3,5 & 5,4 \\
\hline Matéria orgânica $\left(\mathrm{g} \mathrm{dm}^{-3}\right)$ & 14 & 19 \\
\hline$P$ resina $\left(\mathrm{mg} \mathrm{dm}^{-3}\right)$ & 3,0 & 23 \\
\hline $\mathrm{K}\left(\mathrm{mmol}_{\mathrm{c}} \mathrm{dm}^{-3}\right)$ & 0,4 & 6,4 \\
\hline $\mathrm{Ca}\left(\mathrm{mmol}_{\mathrm{c}} \mathrm{dm}^{-3}\right)$ & 1 & 57 \\
\hline $\mathrm{Mg}\left(\mathrm{mmol}_{\mathrm{c}} \mathrm{dm}^{-3}\right)$ & 1 & 12 \\
\hline $\mathrm{H}+\mathrm{Al}\left(\mathrm{mmol}_{\mathrm{c}} \mathrm{dm}^{-3}\right)$ & 31 & 52 \\
\hline $\mathrm{SB}\left(\mathrm{mmol}_{\mathrm{c}} \mathrm{dm}^{-3}\right)$ & 7 & 40 \\
\hline $\mathrm{CTC}\left(\mathrm{mmol}_{\mathrm{c}} \mathrm{dm}^{-3}\right)$ & 54,4 & 101,7 \\
\hline $\mathrm{V} \%$ & 4 & 70 \\
\hline Areia total $\left(\mathrm{g} \mathrm{kg}^{-1}\right)$ & 820 & 260 \\
\hline Silte $\left(\mathrm{g} \mathrm{kg}^{-1}\right)$ & 40 & 40 \\
\hline Argila total $\left(\mathrm{g} \mathrm{kg}^{-1}\right)$ & 140 & 580 \\
\hline
\end{tabular}

Os atributos químicos foram determinados conforme método descrito por Raij et al. (1987). Os atributos físicos foram determinados de acordo com método descrito por Camargo et al. (1986).

\section{Biossólidos}

Foram utilizados biossólidos gerados nas ETEs de Barueri (ETE-Barueri) e Franca (ETE-Franca), que continham alta e baixa concentração de metais, respectivamente. As amostras de biossólidos foram coletadas nas ETEs e aplicadas aos solos in natura. Os atributos químicos dos biossólidos utilizados nos ensaios podem ser vistos no quadro 2 . As doses ótimas de biossólidos foram definidas de acordo com a quantidade de $\mathrm{N}$ necessária para garantir uma produção de 8-10 $\mathrm{Mg}_{\text {ha-1 }}$ de milho (150 kg ha-1 de N). Considerando uma taxa de mineralização de $20 \%$ (CETESB, 1998), as quantidades de biossólidos da ETEBarueri e ETE-Franca, para se obter o equivalente a $150 \mathrm{~kg} \mathrm{ha}{ }^{-1}$ de $\mathrm{N}$-mineralizado, foram de 33,33 e $13,27 \mathrm{Mg} \mathrm{ha}^{-1}$, respectivamente. Considerando a dose ótima, foram utilizados os seguintes tratamentos: 0 , $1,2,4$ e 8 vezes a dose ótima (doses $0,1,2,3$ e 4, respectivamente). As concentrações estimadas de metais no solo após a aplicação de biossólidos na dose ótima (dose 2) encontra-se no quadro 3.

Para o biossólido da ETE-Barueri, as doses 1, 2, 3 e 4 equivalem a 16,66, 33,33, 66,66 e 133,32 $\mathrm{Mg} \mathrm{ha}^{-1}$, respectivamente. Para o biossólido da ETE-Franca, as doses 1, 2, 3 e 4 equivalem a 6,63, 13,27, 26,54 e $54,80 \mathrm{Mg} \mathrm{ha}^{-1}$, respectivamente.

Quadro 2. Atributos químicos dos biossólidos utilizados nos experimentos

\begin{tabular}{|c|c|c|}
\hline \multirow{2}{*}{ Atributo } & \multicolumn{2}{|c|}{ ETE } \\
\hline & Franca & Barueri \\
\hline pH (água) & 7,8 & 10,8 \\
\hline Umidade $65^{\circ} \mathrm{C}\left(\mathrm{g} \mathrm{kg}^{-1}\right)$ & 833,6 & 706,2 \\
\hline Matéria orgânica total $\left(\mathrm{g} \mathrm{kg}^{-1}\right)$ & 746,0 & 380,9 \\
\hline Resíduo mineral total ( $\left.\mathrm{g} \mathrm{kg}^{-1}\right)$ & 254,0 & 610,1 \\
\hline Nitrogênio total $\left(\mathrm{g} \mathrm{kg}^{-1}\right)$ & 56,5 & 22,5 \\
\hline Relação C/N & 7 & 10 \\
\hline$P$ total $\left(\mathrm{g} \mathrm{kg}^{-1}\right)$ & 29,8 & 44,3 \\
\hline $\mathrm{K}$ total $\left(\mathrm{g} \mathrm{kg}^{-1}\right)$ & 1,3 & 1,5 \\
\hline Ca total $\left(\mathrm{g} \mathrm{kg}^{-1}\right)$ & 14,0 & 150,0 \\
\hline $\mathrm{Mg}$ total $\left(\mathrm{g} \mathrm{kg}^{-1}\right)$ & 1,9 & 3,4 \\
\hline $\mathrm{S}\left(\mathrm{g} \mathrm{kg}^{-1}\right)$ & 4,4 & 8,3 \\
\hline $\mathrm{Cu}\left(\mathrm{mg} \mathrm{kg}^{-1}\right)$ & 191 & 487 \\
\hline $\mathrm{Mn}\left(\mathrm{mg} \mathrm{kg}^{-1}\right)$ & 30 & 61 \\
\hline $\mathrm{Zn}\left(\mathrm{mg} \mathrm{kg}^{-1}\right)$ & 2.973 & 1.659 \\
\hline $\mathrm{Cr}\left(\mathrm{mg} \mathrm{kg}^{-1}\right)$ & 949 & 501 \\
\hline $\mathrm{Ni}\left(\mathrm{mg} \mathrm{kg}^{-1}\right)$ & 47 & 242 \\
\hline $\mathrm{Cd}\left(\mathrm{mg} \mathrm{kg}^{-1}\right)$ & $<0,1$ & $<0,1$ \\
\hline $\mathrm{Fe}\left(\mathrm{mg} \mathrm{kg}^{-1}\right)$ & 3.783 & 10.191 \\
\hline $\mathrm{Na}\left(\mathrm{mg} \mathrm{kg}^{-1}\right)$ & 100 & 248 \\
\hline
\end{tabular}

Os atributos químicos foram determinados de acordo com métodos descritos por Eaton et al. (1985). Os resultados são expressos com base no material seco a $65^{\circ} \mathrm{C}$. 
Quadro 3. Concentrações estimadas de metais no solo após a aplicação de biossólidos na dose ótima (dose 2)

\begin{tabular}{ccc}
\hline & \multicolumn{2}{c}{ Biossólido } \\
\cline { 2 - 3 } Metal & ETE-Barueri & ETE-Franca \\
& & \multicolumn{2}{c}{$\mathrm{mg} \mathrm{kg}^{-1}$} \\
\cline { 2 - 3 } & \multicolumn{2}{c}{} \\
$\mathrm{Cu}$ & 35,9 & 7,1 \\
$\mathrm{Mn}$ & 80,1 & 1,1 \\
$\mathrm{Zn}$ & 26,6 & 111,0 \\
$\mathrm{Cr}$ & 12,8 & 1,1 \\
$\mathrm{Ni}$ & $<0,1$ & 1,7 \\
$\mathrm{Cd}$ & 541,1 & $<0,1$ \\
$\mathrm{Fe}$ & & 140,7
\end{tabular}

$\overline{\text { Dados estimados a partir das concentrações apresentadas no }}$ quadro 2 , considerando a aplicação no solo ao equivalente a 33,33 e 13,27 $\mathrm{Mg} \mathrm{ha}^{-1}$ dos biossólidos de Barueri e Franca, respectivamente. Os cálculos das concentrações estimadas de metais foram feitos de acordo com os critérios para a aplicação de biossólidos em solos agrícolas adotados pela CETESB (1998).

\section{Microcosmos}

Os microcosmos foram constituídos de frascos de poliestireno com $200 \mathrm{~g}$ de solo com as respectivas doses de biossólidos. A incubação foi feita por 4, 8, 16, 32 ou 64 dias a $28^{\circ} \mathrm{C}$, em sala climatizada. A umidade dos solos foi mantida em $70 \%$ da capacidade máxima de retenção de água, por meio da adição diária de água destilada. Amostras dos solos imediatamente após a adição de biossólidos (0 dias de incubação) foram utilizadas como controles.

\section{Análises laboratoriais}

Imediatamente após a incorporação dos biossólidos e depois dos períodos de incubação, subamostras de cada unidade experimental foram retiradas para determinação da respiração basal (RB; Anderson, 1982), carbono na biomassa microbiana (CB; Vance et al., 1987), quociente metabólico $\left(q \mathrm{CO}_{2}\right)$ e relação entre a concentração de carbono na biomassa microbiana e carbono orgânico no solo $\left(\mathrm{CB} / \mathrm{C}_{\text {org }}\right.$, Anderson \& Ingram, 1993).

\section{Delineamento experimental e análise estatística}

Foi utilizado um esquema fatorial totalmente casualizado, constituído de cinco doses de biossólidos da ETE-Barueri ou ETE-Franca (0, 1, 2, 4, e 8 vezes a dose ótima), dois solos (argiloso e arenoso) e seis épocas de amostragem $(0,4,8,16,32,64$ dias de incubação), com três repetições por tratamento, totalizando 360 parcelas. As análises de variância (ANOVA) e comparações de médias pelo teste $t$ $(p<0,05)$ foram feitas por meio do programa SYSTAT 8.0 (SPSS, Inc.).

\section{RESULTADOS}

\section{Respiração basal}

De maneira geral, tanto nos tratamentos com biossólidos da ETE-Barueri quanto da ETE-Franca, a $\mathrm{RB}$ foi maior no solo argiloso do que no arenoso e aumentou com o aumento da dose de biossólido aplicada $(p<0,05)$ (Figura 1). A RB foi maior nos tratamentos que receberam as maiores quantidades de biossólidos, em relação aos controles sem biossólidos, independentemente do tipo de solo e da origem do biossólido adicionado (Figura 1). Os maiores incrementos de $\mathrm{RB}$, em relação ao controle sem biossólidos, foram observados imediatamente após a adição dos biossólidos aos solos. No entanto, nos tratamentos com biossólidos, a RB diminuiu significativamente durante o período de incubação, até 64 dias após a adição de biossólidos aos solos (Figura 1).

Após 64 dias de incubação, a RB no solo arenoso que recebeu a dose 1, 2 e 3 de biossólidos da ETEBarueri não diferiu estatisticamente $(\mathrm{p}<0,05)$ daquela observada no solo sem biossólidos (Figura 1a). Já, no solo argiloso, a RB nos tratamentos com a dose 1 de biossólidos da ETE-Barueri não diferiu estatisticamente dos controles sem biossólidos a partir de oito dias de incubação (Figura 1b). No solo arenoso com as doses 1 e 2 de biossólidos da ETE-Franca, a $\mathrm{RB}$ diferiu estatisticamente $(\mathrm{p}<0,05)$ daquela observada no solo sem biossólidos até 32 dias de incubação (Figura 1c). Já, no solo argiloso, após 64 dias de incubação, a RB nos tratamentos com biossólidos da ETE-Franca foi maior do que nos controles sem biossólidos. Diferenças nãosignificativas na RB dos tratamentos com as doses 1 e 2, em relação ao controle sem biossólidos, foram observadas logo após a adição dos biossólidos quatro a oito dias depois (Figura 1c).

\section{Carbono na biomassa microbiana}

Nos tratamentos com biossólidos da ETE-Barueri, o CB foi influenciado de forma significativa $(\mathrm{p}<0,05)$ pelo tipo de solo (Figura 2a,b). No geral, o solo arenoso apresentou maior concentração de CB do que o solo argiloso, exceto após quatro semanas de incubação, quando os tratamentos com solo argiloso apresentaram concentrações mais elevadas de CB do que com o solo arenoso $(\mathrm{p}<0,05)$.

$\mathrm{O}$ CB foi maior nos solos que receberam as doses 3 e 4 de biossólidos da ETE-Barueri, em relação ao controle sem biossólidos $(p<0,05)$. O CB nos tratamentos com biossólidos da ETE-Barueri diminuiu significativamente de acordo com o tempo de incubação $(\mathrm{p}<0,05)$. No geral, após 4 dias de incubação, o CB não diferiu estatisticamente dos valores observados nos solos logo após a aplicação de biossólidos da ETEBarueri e diminuiu aproximadamente $63 \%$ entre $8 \mathrm{e}$ 32 dias, e 78 \% após 64 dias de incubação. 


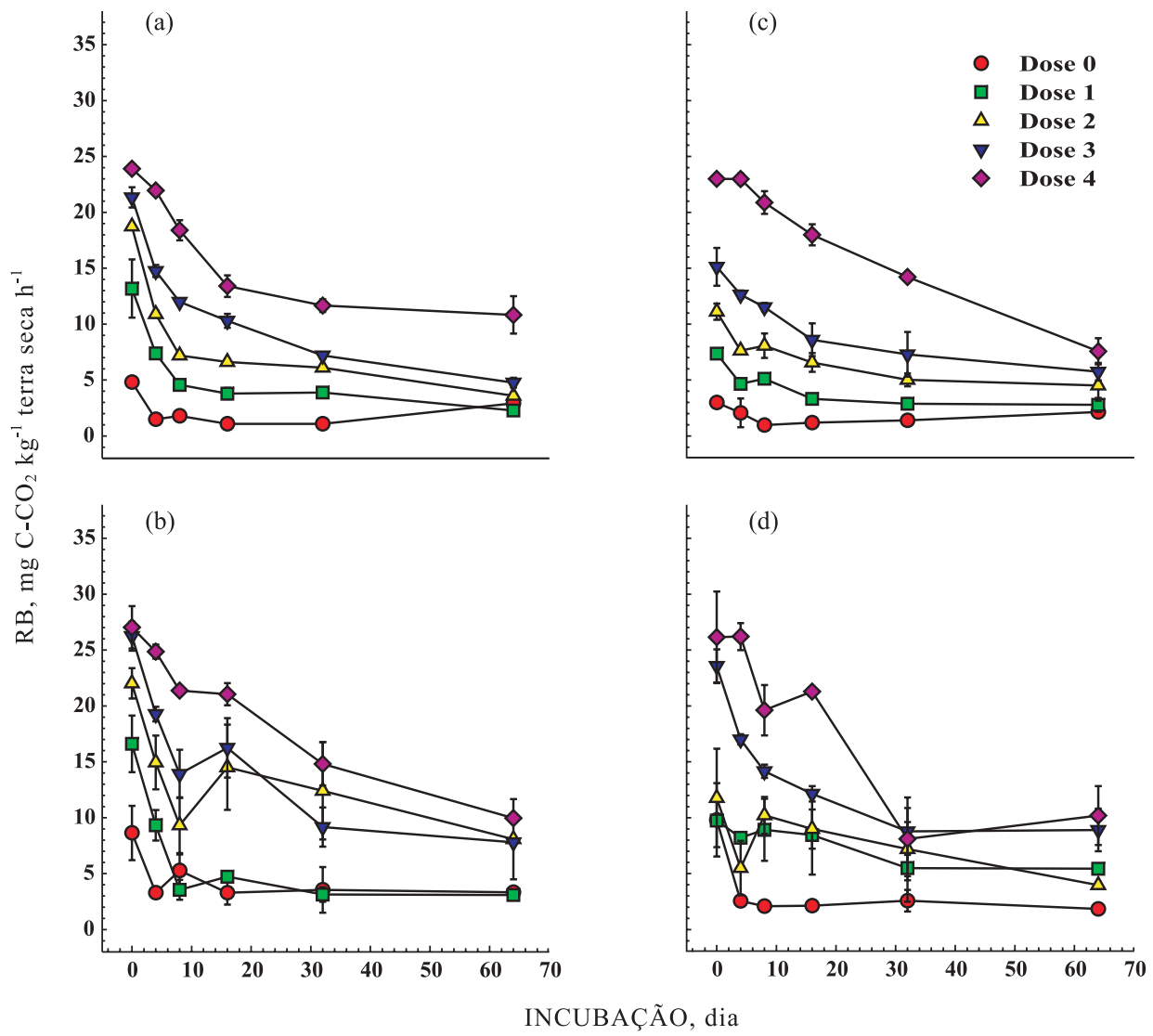

Figura 1. Variação da liberação de $\mathrm{CO}_{2}(\mathrm{RB})$ de solo arenoso (a, c) ou argiloso (b, d) tratado com biossólidos da ETE-Barueri $(a, b)$ ou ETE-Franca $(c, d)$. Os dados são médias de três repetições \pm desvio-padrão da média.

Nos tratamentos com biossólidos da ETE-Franca, o CB foi significativamente maior no solo argiloso do que no arenoso ( $<<0,05$; Figura 2c, d). Solos com biossólidos, independentemente da dose, não apresentaram diferenças significativas para o CB, mas apresentaram incremento significativo em relação ao controle sem biossólidos ( $p<0,05)$.

No geral, o CB apresentou aumento transiente, atingindo um máximo aos quatro dias de incubação e diminuindo significativamente até 64 dias de incubação, em relação ao CB observado imediatamente após a adição de biossólidos (tempo 0; $p<0,05$ ). Em relação ao controle sem biossólidos, o $\mathrm{CB}$ apresentou valores significativamente mais elevados até 8 dias de incubação. Após esse período, as diferenças observadas não foram estatisticamente significativas $(\mathrm{p}<0,05)$.

\section{Quociente metabólico}

Nos solos tratados com biossólidos da ETE-Barueri, o $q \mathrm{CO}_{2}$, no geral, não foi significativamente afetado pelo tipo de solo (Figura 3a,b). $\mathrm{O} q \mathrm{CO}_{2}$ teve aumento significativo nos solos que receberam as doses 2,3 e 4 de biossólidos da ETE-Barueri, em relação aos solos que receberam as doses 0 e $1(p<0,05)$. O tempo de incubação não afetou significativamente o $q \mathrm{CO}_{2}$ nos solos tratados com biossólidos da ETE-Barueri.

Nos solos que receberam biossólidos da ETE-Franca, o $q \mathrm{CO}_{2}$ foi significativamente maior nos tratamentos com solo arenoso, comparado com os tratamentos com solo argiloso ( $p<0,05$; Figura $3 \mathrm{c}, \mathrm{d})$. Em relação ao controle sem biossólidos, o $q \mathrm{CO}_{2}$ aumentou significativamente nos solos que receberam as doses 3 e 4 de biossólidos da ETE-Franca. Nos tratamentos com as menores doses de biossólidos da ETE-Franca, as diferenças não foram estatisticamente significativas em relação ao controle sem biossólidos.

No geral, em solos tratados com biossólidos da ETEFranca, o $q \mathrm{CO}_{2}$ apresentou um aumento transiente, atingindo um máximo depois de 4 dias de incubação e diminuindo posteriormente para valores que não difeririram estatisticamente daqueles observados imediatamente após a adição do biossólido. Nos solos que receberam as doses mais elevadas de biossólidos (doses 3 e 4), aumentos significativos no $q \mathrm{CO}_{2}$, em relação ao tratamento-controle sem biossólidos, foram observados até 8 semanas de incubação $(p<0,05$; Figura 3c,d). 


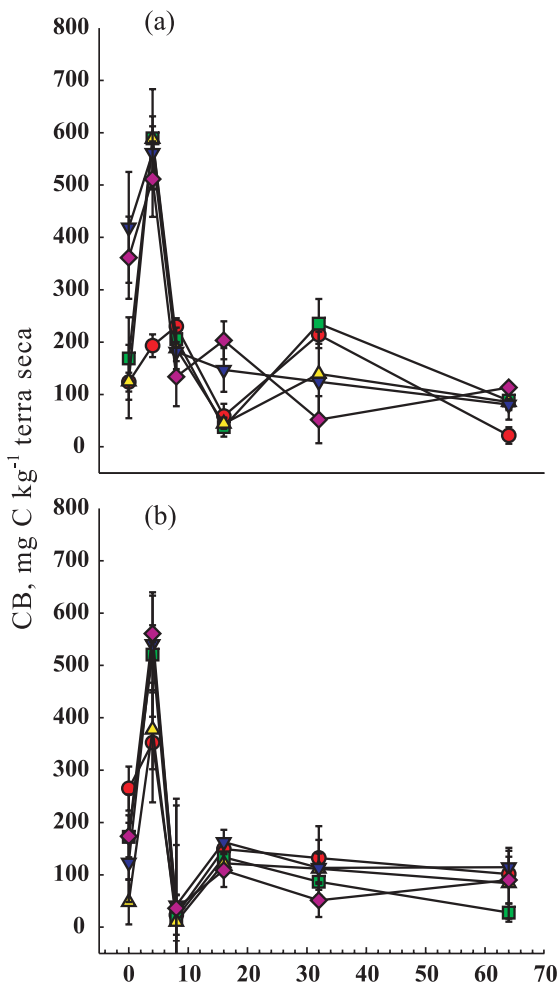

(c)

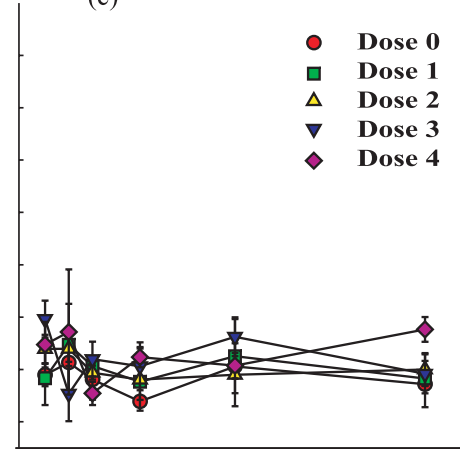

(d)

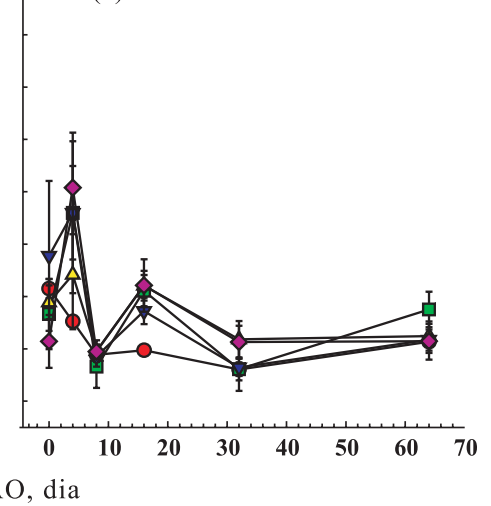

Figura 2. Variação da concentração de carbono na biomassa microbiana (CB) em solo arenoso (a, c) ou argiloso (b, d) tratado com biossólidos da ETE-Barueri (a, b) ou ETE-Franca (c, d). Os dados são médias de 3 repetições \pm desvio-padrão da média.

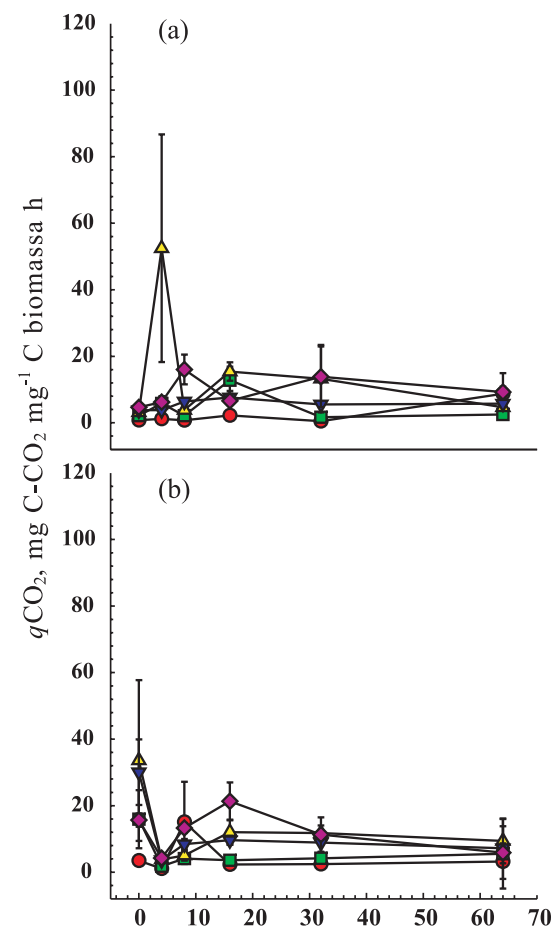

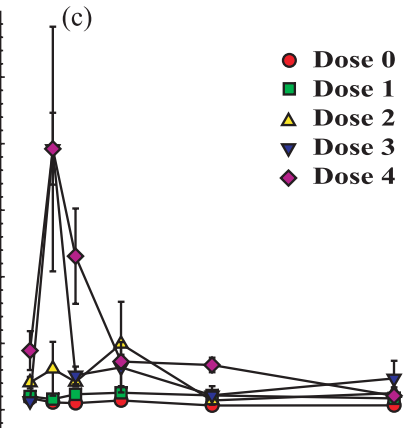

(d)

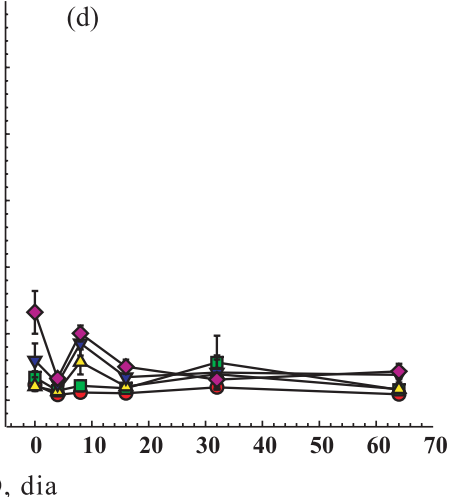

Figura 3. Variação do quociente metabólico $\left(q \mathrm{CO}_{2}\right)$ em em solo arenoso (a, c) ou argiloso (b, d) tratado com biossólidos da ETE-Barueri $(a, b)$ ou ETE-Franca $(c, d)$. Os dados são médias de 3 repetições \pm desviopadrão da média. 


\section{Relação CB/C}

Nos solos tratados com biossólidos da ETE-Barueri, a relação $\mathrm{CB} / \mathrm{C}_{\text {org }}$ foi significativamente afetada pelo tipo de solo (Figura 4a,b). No geral, o $\mathrm{CB} / \mathrm{C}_{\text {org }}$ foi maior no solo arenoso do que no argiloso $(\mathrm{p}<0,05)$. Independentemente do tipo de solo, $\mathrm{CB} / \mathrm{C}_{\text {org }}$ foi maior nos solos que não receberam biossólidos, em relação aos solos que receberam biossólidos da ETE-Barueri. A relação $\mathrm{CB} / \mathrm{C}_{\text {org }}$ nos solos tratados com biossólidos da ETE-Barueri diminuiu significativamente entre quatro e 16 dias de incubação, não sofrendo alterações posteriormente. ( $p<0,05$; Figura $4 a, b)$.

Nos solos que receberam biossólidos da ETE-Franca, $\mathrm{CB} / \mathrm{C}_{\text {org }}$ não foi afetada pelo tipo de solo ou dose de biossólido aplicada ( $<<0,05$; Figura 4c,d). No geral, em solos tratados com biossólidos da ETE-Franca, CB/ $\mathrm{C}_{\text {org }}$ apresentou um aumento transiente, atingindo um máximo depois de 4 dias de incubação e diminuindo posteriormente para valores estatisticamente inferiores àqueles observados imediatamente após a adição do biossólido.

\section{DISCUSSÃO}

Os microrganismos do solo desempenham papéis fundamentais na ciclagem de $\mathrm{C}, \mathrm{N}$ e $\mathrm{S}$, dentre outros elementos. Dependendo do distúrbio causado na comunidade microbiana do solo, alterações significativas na dinâmica de transformação desses elementos podem ocorrer, levando a desequilíbrios de conseqüências imprevisíveis. A incorporação de resíduos orgânicos ao solo geralmente estimula o aumento da biomassa microbiana e sua atividade respiratória e resulta em aumento do teor de matéria orgânica no solo, quando a taxa de biossíntese celular é maior do que a taxa de oxidação do carbono orgânico. No entanto, a presença de metais pesados em níveis tóxicos pode reduzir a eficiência e diversidade metabólica dos microrganismos e, conseqüentemente, reduzir a mineralização da matéria orgânica (Lambais et al., 2005).

No presente estudo, foi verificado aumento imediato da biomassa e atividade microbiana nos solos que receberam tanto os biossólidos da ETE-Barueri, com

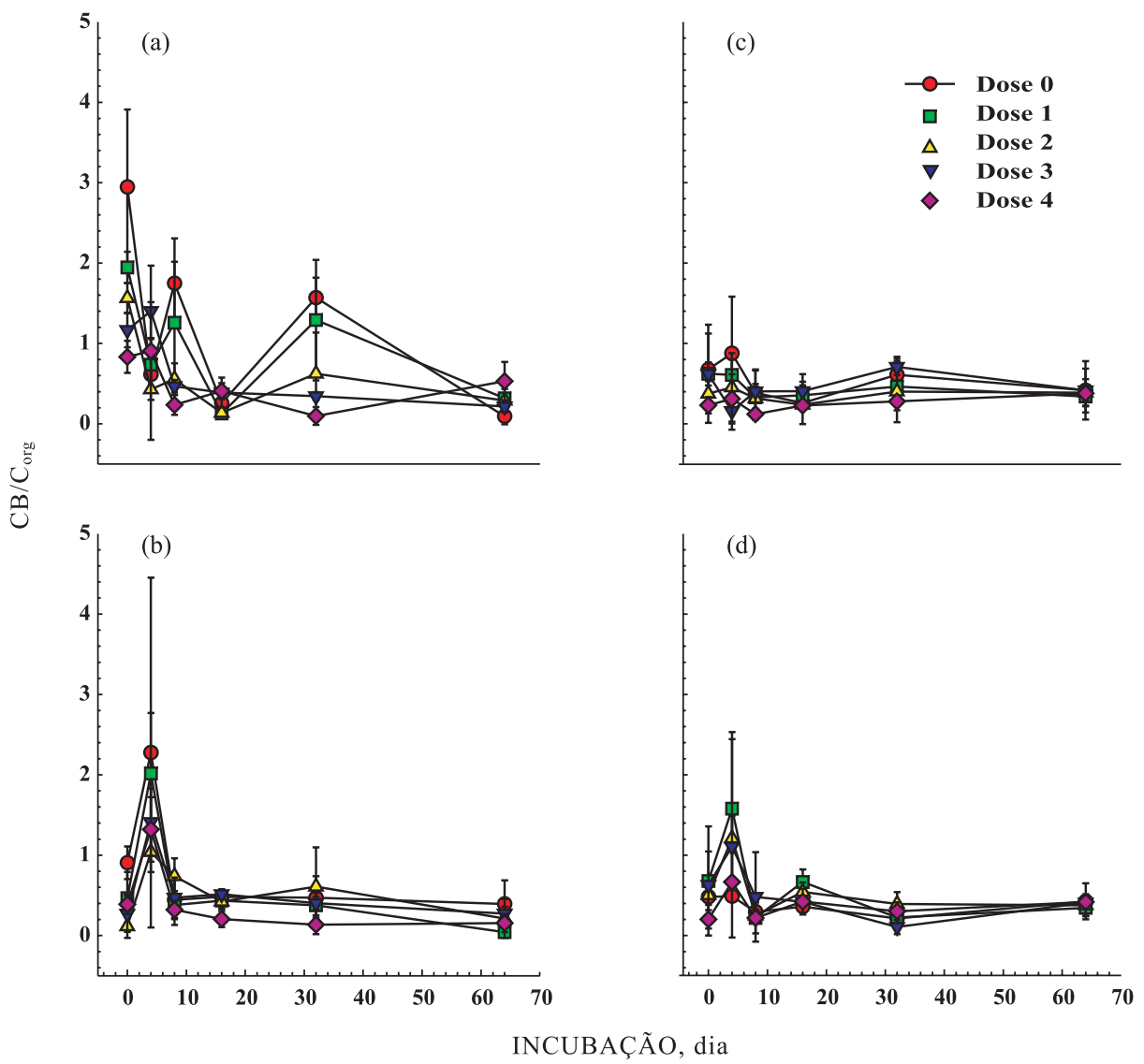

Figura 4. Variação do $\mathrm{CB} / \mathrm{C}_{\text {org }}$ em solo arenoso (a, c) ou argiloso (b, d) tratado com biossólidos da ETEBarueri $(a, b)$ ou ETE-Franca $(c, d)$. Os dados são médias de 3 repetições \pm desvio-padrão da média. 
maior concentração de metais pesados, quanto da ETEFranca, com menor concentração de metais pesados. Foi observado também que em doses até 4 vezes superiores à dose recomendada, não existe efeito inibitório sobre a biomassa e atividade da microbiota. Aumento da biomassa e indução da atividade respiratória dos microrganismos do solo, após a aplicação de biossólidos de ETEs, tem sido observado em inúmeros casos (Barbarick et al., 2004; Fließbach et al., 1994). Em contraste, em alguns casos, decréscimos da biomassa microbiana em solos tratados com biossólidos são observados em experimentos de longa duração e podem ser atribuídos à presença de metais pesados (Dahlin et al., 1997; Chander et al., 2001; Abaye et al., 2005).

É possível que a adição de biossólidos ricos em metais potencialmente tóxicos aos solos possa provocar aumentos transientes da biomassa e atividade microbiana, proporcionado pelo incremento na disponibilidade de carbono orgânico e seleção de microrganismos mais tolerantes a esses metais. Assim, alterações da estrutura das comunidades microbianas em solos tratados com biossólidos poderiam estar ocorrendo, e efeitos inibitórios para o crescimento da biomassa microbiana e sua atividade aeróbia poderiam não ser detectados pela avaliação da comunidade microbiana como um todo (Dahlin et al., 1997; Baath et al., 1998; Sandaa et al., 1999a,b; Chander et al., 2001; Davis et al., 2004; Abaye et al., 2005; Renella et al., 2005a; Akmal et al., 2005; Lorenz et al., 2006).

Em nossos experimentos, alterações na estrutura das comunidades microbianas não foram avaliadas, mas poderiam estar ocorrendo. Tem sido observado que em solos contaminados com metais a diversidade genética de microrganismos pode ser reduzida em mais de 99,9 \%, em relação a solos não contaminados, sem redução do número total de células, e que os táxons eliminados são aqueles mais raros (Gans et al., 2005). Essas alterações nas estruturas das comunidades microbianas podem alterar a dinâmica das transformações de C, N, e S, por exemplo, de forma não-previsível, já que não se conhecem os limites da redundância funcional dos microrganismos do solo.

Muito se tem argumentado sobre a necessidade de indicadores mais precisos de impactos e, ou, estresses sobre a microbiota dos solos (Anderson \& Domsch, 1993; Brendecke et al., 1993; Brookes, 1995; Dahlin et al., 1997). Dentre esses indicadores, o $q \mathrm{CO}_{2}$ tem sido muito utilizado como indicador de estresse na comunidade microbiana. Assim, em comunidades microbianas sujeitas a estresses, maior quantidade de energia seria gasta para manutenção da biomassa microbiana e a quantidade de $\mathrm{C}-\mathrm{CO}_{2}$ perdida pela respiração aumentaria em relação à quantidade de carbono imobilizado na biomassa microbiana.

No presente trabalho, os valores de $q \mathrm{CO}_{2}$ observados nos solos tratados com biossólidos aumentaram significativamente com o aumento da dose de biossólido aplicada ao solo, principalmente entre 8 e 16 dias de incubação. Esses dados indicam que, muito embora efeitos adversos sobre o acúmulo de biomassa e atividade aeróbia não tenham sido observados, a aplicação de biossólidos das ETEs de Barueri ou Franca aos solos pode causar estresse nas comunidades microbianas.

Outro índice que poderia ser utilizado com indicador de estresse na comunidade microbiana seria a relação $\mathrm{CB} / \mathrm{C}_{\text {org. }}$. Em experimentos para avaliar o efeito de $\mathrm{Cd}, \mathrm{Cr}, \mathrm{Cu}, \mathrm{Ni}, \mathrm{Pb}$ e $\mathrm{Zn}$ sobre atributos microbiológicos de solo tratado com biossólidos, uma correlação significativa e negativa entre frações móveis de $\mathrm{Cd}$ e $\mathrm{Ni}$ com a relação $\mathrm{CB} / \mathrm{Corg}$ foi observada (Chaudhuri et al., 2003). Neste trabalho, independentemente do tipo de solo, a relação $\mathrm{CB} / \mathrm{C}_{\text {org }}$ foi significativamente menor nos solos que receberam biossólidos da ETE-Barueri, mas não foi afetada significativamente nos solos que receberam biossólido da ETE-Franca. Os dados de $\mathrm{CB} / \mathrm{C}_{\text {org }}$ e $q \mathrm{CO}_{2}$ obtidos nos experimentos mostram que a imobilização de $\mathrm{C}$ na biomassa microbiana pode ser reduzida em solos que recebem biossólidos ricos em metais.

\section{CONCLUSÕES}

1. No geral, a aplicação de biossólidos ricos em metais tanto em solo arenoso quanto argiloso pode causar aumento transiente na biomassa e atividade da comunidade microbiana, com redução da imobilização de C na biomassa microbiana, quando comparado com biossólidos com menor concentração de metais.

2. Os dados indicam que $q \mathrm{CO}_{2}$ e $\mathrm{CB} / \mathrm{C}_{\text {org }}$ podem ser usados como indicadores de estresse em solos tratados com biossólidos.

\section{AGRADECIMENTOS}

Esse projeto foi financiado pela FAPESP (2000/ 05166-4). MRL é bolsista de Produtividade em Pesquisa do CNPq. JBC foi bolsista da CAPES.

\section{LITERATURA CITADA}

ABAYE, D.A.; LAWLOR, K.; HIRSCH, P.R. \& BROOKES, P.C. Changes in the microbial community of an arable soil caused by long-term metal contamination. Eur. J. Soil Sci., 56:93-102, 2005.

AKMAL, M.; WANG, H.Z.; WU, J.J.; XU, J.M. \& XU, D.F. Changes in enzymes activity, substrate utilization pattern and diversity of soil microbial communities under cadmium pollution. J. Environ. Sci., 17:802-807, 2005. 
ANDERSON, T.H. \& DOMSCH, K.H. The metabolic quotient for $\mathrm{CO}_{2}\left(\mathrm{qCO}_{2}\right)$ as a specific activity parameter to assess the effects of environmental-conditions, such as $\mathrm{pH}$, on the microbial biomass of forest soils. Soil Biol. Biochem., 25:393-395, 1993.

BAATH, E.; DIAZ-RAVINA, M.; FROSTEGARD, A. \& CAMPBELL, C.D. Effect of metal-rich sludge amendments on the soil microbial community. Appl. Environ. Microbiol., 64:238-245, 1998.

BANERJEE, M.R.; BURTON, D.L. \& DEPOE, S. Impact of sewage sludge application on soil biological characteristics. Agric. Ecosyst. Environ., 66:241-249, 1997.

BARBARICK, K.A.; DOXTADER, K.G.; REDENTE, E.F. \& BROBST, R.B. Biosolids effects on microbial activity in shrubland and grassland soils. Soil Sci., 169:176-187, 2004

BRENDECKE, J.W.; AXELSON, R.D. \& PEPPER, I.L. Soil microbial activity as an indicator of soil fertility - Long term effects of municipal sewage-sludge on an arid soil. Soil Biol. Biochem., 25:751-758, 1993.

BROOKES, P.C. The use of microbial parameters in monitoring soil. The use of microbial parameters in monitoring soil pollution by heavy-metals. Biol. Fert. Soils, 19:269-279, 1995.

CAMARGO, O.A.; MONIZ, A.C.; JORGE, J.A. \& VALADARES, J.M.A.S. Métodos de análise química, mineralógica e física de solos do Instituto Agronômico de Campinas. Campinas, Instituto Agronômico de Campinas, 1986. 94p. (Boletim Técnico, 106)

CARMO, J.B.; ANDRADE, C.A.; CERRI, C.C. \& PICCOLO, M. Disponibilidade de nitrogênio e fluxos de $\mathrm{N}_{2} \mathrm{O}$ a partir de solo sob pastagem após aplicação de herbicida. R. Bras. Ci. Solo, 29:735-746, 2005.

CHANDER, K.; DYCKMANS, J.; JOERGENSEN, R.G.; MEYER, B. \& RAUBUCH, M. Different sources of heavy metals and their long-term effects on soil microbial properties. Biol. Fert. Soils, 34:241-247, 2001.

CHAUDHURI, D.; TRIPATHY, S.; VEERESH, H.; POWELL, M.A. \& HART, B.R. Relationship of chemical fractions of heavy metals with microbial and enzyme activities in sludge and ash-amended acid lateritic soil from India. Environ. Geol., 45:115-123, 2003.

COMPANHIA DE TECNOLOGIA E SANEAMENTO AMBIENTAL - CETESB. Aplicação de biossólidos em áreas agrícolas - critérios para projetos e operação. São Paulo, CETESB, 1998. 36p.

DAHLIN, S.; WITTER, E.; MARTENSSON, A.; TURNER, A. \& BAATH, E. Where's the limit? Changes in the microbiological properties of agricultural soils at low levels of metal contamination. Soil Biol. Biochem., 29:1405-1415, 1997.

DAVIS, M.R.H.; ZHAO, F.J. \& MCGRATH, S.P. Pollutioninduced community tolerance of soil microbes in response to a zinc gradient. Environ. Toxicol. Chem., 23:2665-2672, 2004 .

EATON, A.D.; CLESCERI, L.S. \& GRENNBERG, E.E. Standard methods for the examination of water and waste water. 19.ed. Washington, APHA, AWWA, WEF, 1995. 1082p.
FLIEBBACH, A.; MARTENS, R. \& REBER, H.H. Soil microbial biomass and microbial activity in soils treated with heavymetal contaminated sewage-sludge. Soil Biol. Biochem., 26:1201-1205, 1994.

FROSTEGARD, A.; TULIND, A. \& BAATH, E. Phospholipid fatty acid composition, biomass, and activity of microbial communities from two soil types experimentally exposed to different metals. Appl. Environ. Microbiol., 54:36053617, 1993.

GANS, J.; WOLINSKY, M. \& DUNBAR, J. Computational improvements reveal great bacterial diversity and high metal toxicity in soil. Science, 309:1387-1390, 2005.

KANDELER, E.; KAMPICHLER, C. \& HORAK, O. Influence of heavy metals on the functional diversity of soil microbial communities. Biol. Fert. Soils, 23:299-306, 1996.

KNIGHT, B.P.; McGRATH, S.P. \& CHAUDRI, A.M. Biomass carbon measurements and substrate utilization patterns of microbial populations from soils amended with cadmium, copper or zinc. Appl. Environ. Microbiol., 63:3943, 1997.

LAMBAIS, M.R.; CURY, J.C.; MALUCHE-BARETTA, C.R. \& BÜLL, R.C. Diversidade microbiana nos solos: definindo novos paradigmas. In: VIDAL-TORRADO, P.; ALLEONI, L.R.F.; COOPER, M.; SILVA, A.P. \& CARDOSO, E.J., orgs. Tópicos em ciência do solo. Viçosa, MG, Sociedade Brasileira de Ciência do Solo, 2005, v.4. p.43-84.

LEITA, L.; DENOBILI, M.; MUHLBACHOVA, G.; MONDINI, C.; MARCHIOL, L. \& ZERBI, G. Bioavalability and effects of heavy-metals on soil microbial biomass survival during laboratory incubation. Biol. Fert. Soils, 19:103-108, 1995.

LORENZ, N.; HINTEMANN, T.; KRAMAREWA, T.; KATAYAMA, A.; YASUTA, T.; MARSCHNER, P. \& KANDELER, E. Response of microbial activity and microbial community composition in soils to long-term arsenic and cadmium exposure. Soil Biol. Biochem., 38:1430-1437, 2006.

McGRATH, S.P. \& CUNLIFFE, C.H. A simplified method for the extraction of the metals $\mathrm{Fe}, \mathrm{Zn}, \mathrm{Cu}, \mathrm{Ni}, \mathrm{Cd}, \mathrm{Pb}, \mathrm{Cr}, \mathrm{Co}$ and $\mathrm{Mn}$ from soils and sewage sludges. J. Sci. Food Agric., 36:794-798, 1985 .

RAIJ, B. van; QUAGGIO, J.A.; CANTARELLA, H.; FERREIRA, M.E.; LOPES, A.S. \& BATAGLIA, O.C. Análise química do solo para fins de fertilidade. Campinas, Fundação Cargill, 1987. 170p.

RENELLA, G.; MENCH, M.; GELSOMINO, A.; LANDI, L. \& NANNIPIERI, P. Functional activity and microbial community structure in soils amended with bimetallic sludges. Soil Biol. Biochem., 37:1498-1506, 2005a.

RENELLA, G.; MENCH, M.; LANDI, L. \& NANNIPIERI, P. Microbial activity and hydrolase synthesis in long-term Cd-contaminated soils. Soil Biol. Biochem., 37:133-139, 2005b.

SANDAA, R. A.; ENGER, O. \& TORSVIK, V. Abundance and diversity of Archaea in heavy-metal-contaminated soils. Appl. Environ. Microbiol., 65:3293-3297, 1999a. 
SANDAA, R. A.; TORSVIK, V.; ENGER, O.; DAAE, F. L.; CASTBERG, T. \& HAHN, D. Analysis of bacterial communities in heavy metal-contaminated soils at different levels of resolution. Fems Microbiol. Ecol., 30:237-251, 1999b.

SASTRE, I.; VICENTE, M.A. \& LOBO, M.C. Influence of the application of sewage sludges on soil microbial activity. Biores. Technol., 57:19-23, 1996.
TORSVIK, V.; DAAE, F.L.; SANDAA, R.A. \& OVREAS, L. Novel techniques for analysing microbial diversity in natural and perturbed environments. J. Biotechnol., 64:53-62, 1998.

VIG, K.; MEGHARAJ, M.; SETHUNATHAN, N. \& NAIDU, R. Bioavailability and toxicity of cadmium to microorganisms and their activities in soil: A review. Adv. Environ. Res., 8:121-135, 2003. 